\title{
CONHECIMENTO E ACESSO À SAÚde BUCAL DE UM GRUPO DE GESTANTES ADOLESCENTES
}

Mayra Salgado MALUCELLI, Elise Alves MIRANDA, Bruna Basso FONSECA, Maxwelli Fernanda TAUCHERT, Rayza Santiago WAPNIARZ, Sergio Luiz GUANDALINI

Existe uma escassez de dados em relação ao conhecimento e acesso à saúde bucal de adolescentes gestantes. Portanto, procurou-se avaliar o grau de conhecimento de gestantes adolescentes sobre saúde bucal, bem como alguns indicadores de acesso à atenção odontológica. Os dados coletados foram obtidos por meio de questionário desenvolvido para esta pesquisa, aprovada pelo comitê de ética, em 33 gestantes adolescentes, realizados no período de 12 meses. A média de idade da amostra foi de 15,5 anos, sendo que a maioria $(n=19)$ encontrava-se no terceiro trimestre de gestação. Visitaram o dentista durante o período gestacional $60,6 \%(n=20)$ e receberam orientações sobre cuidados bucais $51,5 \%(n=17)$. Entretanto apenas 2 gestantes receberam algum tipo de material instrucional. Em relação à saúde bucal durante a gravidez, $81 \%(n=27)$ relataram não ter mudado seus hábitos de higiene e $75 \% \quad(n=25)$ das adolescentes não notaram alterações significativas na mucosa. Apenas $26,7 \%(n=8)$ responderam saber cuidar da boca e dos dentes do bebê. Apesar da maioria das adolescentes ter visitado 0 dentista durante a gestação, observa-se um desconhecimento em relação aos cuidados bucais da mãe e do bebê. Há necessidade de aumentar o nível de informação e acesso à atenção odontológica no grupo pesquisado.

Palavras-chave: Gestantes; Saúde bucal; Atenção à saúde 